\title{
Does Manufacturing Industry Agglomeration Aggravate Regional Pollution? -- Evidence from 271 Prefecture-level Cities in China
}

\author{
Meiying Kong ${ }^{*}$, Hua Wan², Qiuming Wu ${ }^{1}$ \\ ${ }^{1}$ School of Economics and Management, Fuzhou University, Fuzhou 350100, China \\ ${ }^{2}$ School of Economics and Management, East China Jiangtong University, Nanchang 330000, China \\ *to whom all correspondence should be addressed: e-mail: kongmy1215@163.com
}

\section{GRAPHICAL ABSTRACT}

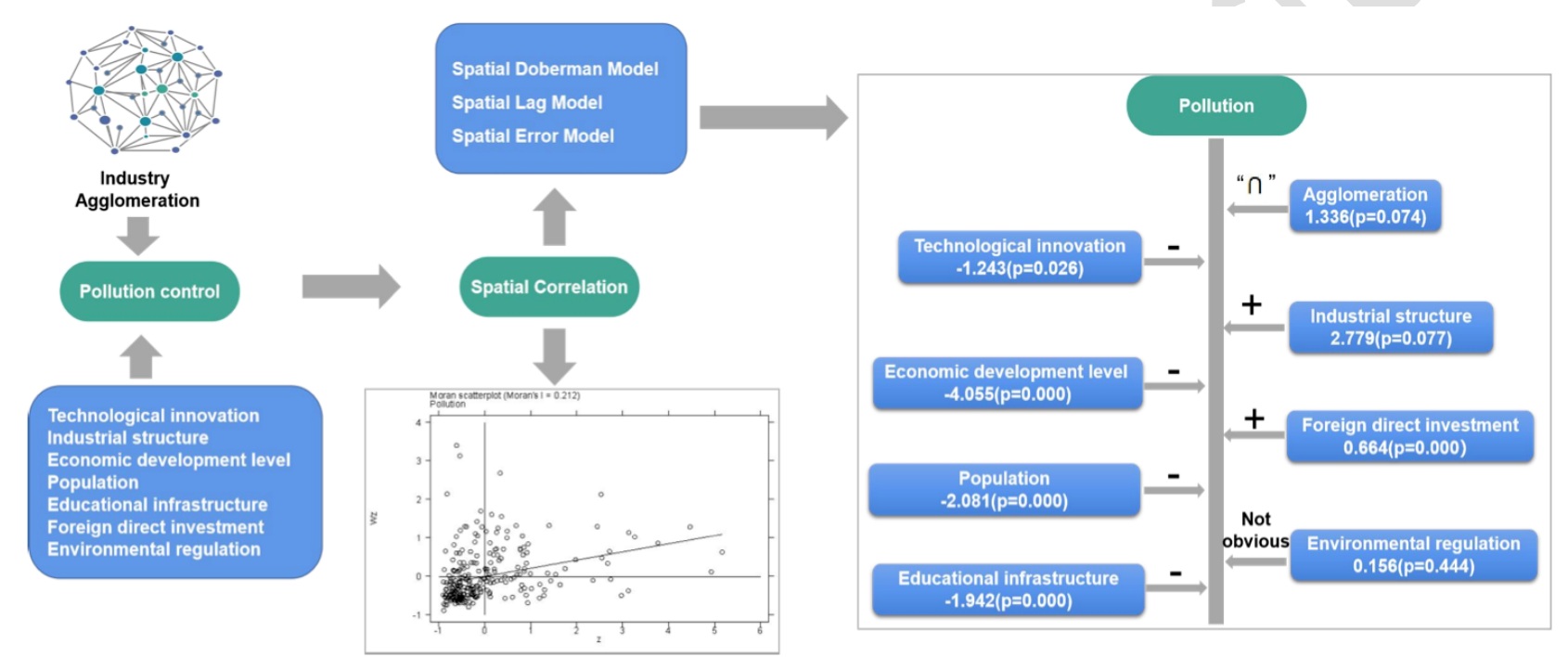

\begin{abstract}
To find out the relationship between industrial agglomeration and environmental pollution, this paper carried out empirical research on the panel data collected from 271 prefecture-level cities in China from 2004 to 2017 through a spatial panel econometric model. It reviewed the influence of agglomeration externality on environmental pollution. The results detected an inverted "U"-shaped relationship between manufacturing industry agglomeration and environmental pollution nation-wide. The manufacturing industry agglomeration level at the inflection point was 0.652 , suggesting that prefecture-level cities suffered severe environmental pollution problems. At the regional level, the manufacturing industry agglomeration in eastern and western China had a significant adverse effect on environmental pollution. In the central China, the relationship between manufacturing industry agglomeration and pollution was " $\mathrm{N}$ " -shaped. The manufacturing industry agglomeration levels in most prefecture-level cities were between the two inflection points. The environmental pollution aggravated as the manufacturing industry agglomeration level rose in the range. As for cities in the northeastern region, manufacturing industry agglomeration has no direct causal relationship with environmental pollution.
\end{abstract}

Keywords: Industrial agglomeration, Environmental pollution, Technological innovation, Space measurement

\section{Introduction}


Since the 1990s, when economic globalization accelerated, industry distribution, instead of being dispersed, agglomerated. Industrial agglomeration, a geographical concentration phenomenon, grew to be a new form of industrial organization emerging worldwide. It also serves as a "growth pole" promoting the national and regional economy. Due to industrial agglomeration in the spatial economy, localized growth has become a prominent economic growth phenomenon (Fujita and Thisse, 2002). As economic factors flowing faster and trade barriers being broken, the industrial agglomeration effect grew more robust rather than weakened. A substantial number of theoretical and empirical researches have confirmed that industrial agglomeration plays a positive role in promoting industrial growth, facilitating resource allocation optimization, and enhancing industrial competitiveness in the world (Markusen and Ann, 1996; Porter, 1990). At the same time, industrial agglomeration brings together production activities and leads to population agglomeration, creating tremendous pressure on ecology and the environment (Cetin and Karafaki, 2020). As environmental pollution attracts considerable attention, how to achieve a balance between environmental protection and economic development becomes one of the research headlines in recent years.

Since the reform and opening-up, China's economy has been thriving for the past four decades. China now is the world's second-largest economy and the world's largest manufacturer. As China built up a socialist market economy system with Chinese characteristics, the country issued and implemented a series of opening-up policies since the 1980s, promoting manufacturing industry agglomeration towards a quality development (Yang et al., 2020). The four major manufacturing industry agglomeration regions of Pearl River Delta, Yangtze River Delta, Bohai Rim, and Midwest forms. Simultaneously, China's environment is under great pressure. Pollutants discharged by manufacturing industries increase exponentially despite higher environmental protection standards and strict legal enforcement. Take sulfur dioxide emission as an example, among all other pollutants. According to statistics, the total sulfur dioxide emissions generated by Chinese industries fell from 21.1975 million tons in 2017 to 15.5676 million tons; On the contrary, the manufacturing industry emitted more sulfur dioxide with an emission surging from 7.638 million tons to 8.709 million tons. As a result, the manufacturing sector contributed $41.08 \%$ to the national sulfur dioxide emission, higher than the proportion of $36.03 \%$ in 2017 . Some regions, however, tells a different story. Take Zhejiang Province for example. Its total industrial sulfur dioxide emissions decreased from 776000 tons in 2007 to 532000 tons, so did the proportion of manufacturing sulfur dioxide emission accounting for the total industrial emissions decrease from $33.35 \%$ in 2007 to $29.7 \%$. Such a comparison raises a question. From the whole country's perspective, pollutant emission is positively correlated to manufacturing industry agglomeration, but the relationship was reversed in Zhejiang Province. These two distinctive relations intrigued us to explore the specific correlation between manufacturing industry agglomeration and pollutant emissions (Yu et al., 2020). What role does industrial agglomeration play in exacerbating pollution? Is it possible the main reason for regional environmental pollution?

To solve the above problems, this paper studies the panel data of 271 prefecture-level cities in China in 2004-2017 to explore relationship between manufacturing industry agglomeration and environmental pollution. By clarifying the relationship between the two, we deepened the theoretical understanding to the relationship between economic growth and environmental protection, based on which we further evaluate the development model of industrial agglomeration to formulate more scientific and reasonable development policies (Wang et al., 2020). If the industrial agglomeration produces more pollution into the environment and no longer "effective", it is necessary to balance economic interests with environmental costs in decision-making. This research is undeniable significant for countries and regions with vulnerable natural environment when seeking economic growth through industrial agglomeration. However, if the industrial agglomeration is helpful to reduce environmental pollution, such a model will offer a solution to pollution 
treatment beyond economic development (Liu et al., 2019).

In the following sections, Section 2 provides a literature review of concepts and models; Section 3 establishes models and indicators to verify the relationship between manufacturing industry agglomeration and environmental pollution; Section 4 analyzes the results of empirical research; Section 5 discusses the research results and puts forward policy implications (Yelmen et al., 2019).

\section{Literature review}

Industrial agglomeration refers to the clustering of a large number of firms in a related area. Competition exists with collaboration in the cluster where institutions share common characters and supplementary to each other. These companies enhance their competitiveness and share the facilities, markets, knowledge, and information in the area where the corporate residents enjoy the scale, agglomeration, external effect created by the industrial clusters. Scholars have yet to reach a consensus on the relationship between industrial agglomeration and environmental pollution. Some scholars proposed that industrial agglomeration exacerbated environmental pollution. Virkanen (1998) proved that industrial agglomeration exacerbated water and air pollution. Leeuw et al. (2001) also verified the scale of industrial agglomeration was correlated with urban atmospheric quality through empirical research. Rena et al. (2003) found that industrial agglomeration led to land overuse and water quality decrease in the rapid urbanization through empirical research on time series data of Shanghai in 1947-1996. Moriki et al. (2006) proved that the scale expansion driven by industrial agglomeration increased regional pollutant emissions. Andersson and Loof (2011) believed that the scale effect and congestion effect on industrial agglomeration increased pollutant emissions. Some other scholars, on the contrary, suggested that industrial agglomeration can improve regional environmental quality. They believed that industrial agglomeration means many enterprises concentrate geographically, and their relationship would stimulate technological innovation and knowledge spillover effect (Feldman and Maryann, 1999), promote environmental protection and ecological production technology that would mitigate the pollution generated in the industrial development. Chen and $\mathrm{Hu}$ (2008) took data from the Yangtze River Delta region of China in 1978-2005 as samples. Their empirical research found that if industries and firms cluster naturally, the aggregation would benefit residents, technological development, and industrial competitiveness and optimize the regional development environment. Zeng and Zhao (2009) constructed a spatial economic growth model covering two countries and two sectors. The result showed that manufacturing industry agglomeration would help reduce the "pollution shelter" effect. When studying the hypothesis of "pollution shelter", some scholars found that Foreign Direct Investment (FDI) facilitated industrial agglomerating (Dong et al., 2012), stimulating the increasing returns to scale of pollution control, thus improving the host country's environment quality instead of deteriorating it (He, 2006). Furthermore, some scholars found that environmental pollution is not distinctively related to industrial agglomeration. The environmental externalities of industrial agglomeration have positive and negative superposition effects, which are complex. Under the influence and restriction of other factors, the two subjects have demonstrated "U" -shaped, "N" -shaped, and inverted "N" -shaped and other nonlinear relationships with apparent threshold characteristics. In contrast, some studies have confirmed that there is no inevitable causality between the two (Cao and Lin, 2016; Li et al., 2010; Liu et al., 2018; Tan and Zhang, 2015; Xie and Yuan, 2006; Yang, 2015).

By reviewing the above literature, we find that, first, scholars did not reach consensus on the relationship between industrial agglomeration and pollution, thus pending more evidences to verify the relationship before offering scientific reference for policy makers. Second, most of the researches are carried out at the provincial or first tier metropolitan levels, data from prefecture-level city level whose individual 
heterogeneity is better controlled are less studied. Third, most scholars use empirical method to study the mechanism of industrial agglomeration on environmental pollution with traditional panel data model, few use spatial panel econometric model. Since environmental pollution, especially air pollution, could easily transfer into regional specific pollution to follow natural conditions. Given this, environmental pollution's regional heterogeneity will produce significant spatial correlation (Liu et al., 2015). The research results would be biased if the study ignores the spatial spillover effect. In view of this, we constructed a spatial panel econometric model based on the panel data of manufacturing sub-industries of 271 prefecture-level cities in China in 2004-2017. The model carried out empirical research on the relationship between industrial agglomeration and environmental pollution and explored the regional characters of the influence that manufacturing industry agglomeration would have on environmental pollution. By clarifying such a complex dynamic relationship, we intend to provide theory basis in terms of industrial agglomeration management and environment treatment policy-making.

\section{Research method and design}

\subsection{Research method}

(1) Spatial correlation test

Regional economic environment and industrial policies are subject to changes of the distance of adjacent areas. The shorter the distance, the stronger the spatial correlation (Anselin, 1998). Industrial agglomeration affects the distribution and flow of industrial elements from region to region, among which, pollutant discharge, especially air pollution, is particularly apparent (Marion et al., 2015). Against such background, we assume that manufacturing industry agglomeration is spatially correlated with pollution discharged into the environment. Moran'I is the appropriate formular that explores the spatial correlation between economic elements (Ord and Getis, 2010). This paper used the index to test the spatial correlation between manufacturing industry agglomeration and environmental pollution in 271 Chinese prefecture-level cities. The formula was as follows:

$$
\text { Moran' } I=\frac{\sum_{i=1}^{n} \sum_{j=1}^{n} W_{i j}\left(Y_{i}-\bar{Y}\right)\left(Y_{j}-\bar{Y}\right)}{S^{2} \sum_{i=1}^{n} \sum_{j=1}^{n} W_{i j}}
$$

Where: $S^{2}=\frac{1}{\mathrm{n}} \sum_{\mathrm{i}=1}^{n}\left(Y_{i}-\bar{Y}\right)^{2} ; \bar{Y}=\frac{1}{n} \sum_{i=1}^{n} Y_{i}, \mathrm{Y}_{\mathrm{i}}$ is the observed value for the $\mathrm{i}^{\text {th }}$ region; $\mathrm{n}$ represents total regions; $\mathrm{W}_{\mathrm{ij}}$ was the $(\mathrm{i}, \mathrm{j})$ element in the spatial weight matrix $\mathrm{W}$. Moran'I value falls in the range of $[-1,1]$. If the value is less than 0 , the correlation is negative, 0 means not related, and value greater than 0 indicates positive correlation. A greater absolute value suggests a stronger spatial correlation, and a smaller absolute value, a weaker spatial correlation.

\section{(2) Spatial weight matrix}

Before having the spatial econometric analysis, we need to measure the spatial distance between regions, which is depend on the spatial weight matrix. Wij, as its element, describes the spatial relationship between City $i$ and City $j$. The $0-1$ adjacent matrix (where, the two regions had a common boundary, the value equals 1 , otherwise the value is 0 ) is the often used setting method.

\subsection{Research design}

(1) Index selection 
The pollution (Pollution) was the explained variable in this paper. This item is always measured by pollutant emission. The total pollutant emission index, however, does not remove the impact of regional economic development differences. Since sulfur dioxide is a typical industrial emission in China, this paper based on other scholars research use sulfur dioxide emission per unit as a measurement of pollution level in the environment ( $\mathrm{Lu}$ et al., 2017). The value reflects the ratio of total sulfur dioxide emission to GDP in a prefecture-level city.

Manufacturing industry agglomeration level (Agg) is the core explanatory variable in this paper. Since location entropy index eliminates the impact due to regional scale difference, it may reflect the spatial distribution of geographical elements more clearly. The paper uses location entropy to obtain the level of manufacturing industry agglomeration. Its formula was as follows:

$$
\mathrm{L} Q_{\mathrm{it}}=\frac{\mathrm{M}_{\mathrm{it}} / \mathrm{Q}_{\mathrm{it}}}{\mathrm{M}_{\mathrm{t}} / \mathrm{Q}_{\mathrm{t}}}
$$

Where $\mathrm{LQ}_{\mathrm{it}}, \mathrm{M}_{\mathrm{it}}, \mathrm{Q}_{\mathrm{it}}$ are the location entropy index, gross manufacturing revenue and GDP of the $\mathrm{i}^{\text {th }}$ prefecture-level city in the $t$ period, respectively; $\mathrm{M}_{\mathrm{t}}$ is the gross manufacturing revenue, and $\mathrm{Q}_{\mathrm{t}}$ is GDP in the national $t$ period.

Given the significant heterogeneity of each prefecture-level city, the econometric model adds in the following seven control variables to prevent any variables from being omitted:

(1) Technological innovation (tech). Technological innovation provides enterprises clean technology to reduce pollutant emissions and thus reduce environmental pollution. This paper selected the number of authorized patent holdings per 10000 people in the prefecture-level cities at the end of the year to measure technological innovation level.

(2) Industrial structure (str). The impact of industrial structure on environment is different at each economic developing level. The paper uses the ratio of secondary industry and tertiary industry to measure the industrial structure. If the ratio is above 1, manufacturing plays a bigger role in the economic structure, while the structure tends to be dependent on services if the ratio is below 1 .

(3) Economic development level (econ). Environmental pollution is closely related to the level of economic development (Grossman and Krueger, 1992). At initial phase, industrialization growth would inevitably lead to natural resources overexploitation and a surge in waste emissions (Dasgupta et al., 2002). As the economy evolves, social development requires better environmental quality, urging policy-makers to formulate stricter environmental protection standards and tax systems to protect the environment. This paper uses per capita GDP to measure the level of economic development.

(4) Population (pop). A larger population promotes production agglomeration and clustering of lifestyle, which translate into a higher consumption demand of residents for living materials and higher ecological pressure. This paper uses the permanent resident density in each region to measure the population size.

(5) Educational infrastructure (edu). Generally, a region would have more high-quality labor if the local education level is higher, thus laying a talent reserve for science and technology innovation. In addition, better educated residents are usually more environmentally aware and are more willing to spending on environmentally friendly products, forcing enterprises to innovate environmental protection technology, which helps improve environmental conditions. This paper uses the level of education expenditure in the prefecture-level city to measure the education supportive foundation.

(6) Foreign direct investment (fdi). Foreign direct investment (FDI) may introduce a "substitution effect" on pollution activities, which is the "pollution haven" hypothesis (Taylor, 1995; Wagner and Timmins, 2009). 
Current researches categorize FDI into three types. The first type is the stock of FDI in all regions (Liang, 2006). The second is presented by the flow of FDI (Jorgenson, 2007). The third type is illustrated by the proportion of the output value of foreign owned industrial enterprises to GDP. Given the research sample, the purpose and the availability of data, this paper adopts the proportion of total FDI utilized by the prefecture-level city to local GDP as measurement. In the calculation process, the unit of currency was converted into RMB based on the annual average exchange rate of RMB to US dollar in the current year.

(7) Environmental regulation (er). Environmental regulation is the rules and regulations issued by the government to restrain environmental pollution. Stringent environmental regulation requires greater investment in environmental control and protection, which would reduce pollution. Given the availability of data in prefecture-level cities, this paper uses the proportion of staff number in the ecological and environment sector (including water conservancy management, public facilities management, ecological protection and environmental governance) to the total population engaged in the industry.

(2) Data sources and preprocessing

The paper collected the index data it needed from the China Urban Statistics Yearbook (2005 2018) and the China Environmental Statistics Yearbook (2005 2018). The statistical yearbooks published by provinces and cities as well as the statistical bulletin of national economic and social development offer supplemented data. The paper deleted prefecture-level cities (such as Lhasa, Xigaze, Changdu, Linzhi, Shannan, Naqu, Haidong, Danzhou, Turpan, Hami, etc.) fail to offer enough data, newly established prefecture-level cities and city-county merged ones (such as Tongren, Bijie, Chaohu, Sansha, Hengshui, etc.). Finally, the panel data sample is made up of 271 prefecture-level cities in China in 2004-2017. Moreover, to eliminate the influence of price factors and ensure the data comparable, this paper deflates the GDP per capita with the GDP index (with 2000 as the base period). To eliminate the influence of heteroscedasticity, all the absolute variable data in this paper were logarithmic.

\section{(3) Setting of spatial measurement model}

Table 1 shows the Moran'I results of pollution level and manufacturing industry agglomeration level in 271 prefecture-level cities in China in 2004 - 2017. The result indicates that Moran'I value reflecting environmental pollution level and manufacturing industry agglomeration level in the past years was above 0 , and passed the $1 \%$ significant test. Such an outcome suggests that environmental pollution is positively correlated with manufacturing industry agglomeration in terms of spatial layout. Therefore, when exploring how manufacturing industry agglomeration impact pollution, the model may be endogenous which produces bias of research results if the spatial correlation is neglected.

Table 1. Moran'I of environmental pollution level and manufacturing industry agglomeration level of 271 prefecture-level cities in China in $2004-2017$

\begin{tabular}{|l|l|l|l|l|l|l|l|l|l|l|l|l|l|l|}
\hline Year & 2004 & 2005 & 2006 & 2007 & 2008 & 2009 & 2010 & 2011 & 2012 & 2013 & 2014 & 2015 & 2016 & 2017 \\
\hline \multirow{4}{*}{$\begin{array}{l}\text { polluti } \\
\text { on }\end{array}$} & $0.185 *$ & $0.204 *$ & $0.143 *$ & $0.208 *$ & $0.229 *$ & $0.207 *$ & $0.226 *$ & $0.340 *$ & $0.260 *$ & $0.262 *$ & $0.271 *$ & $0.185 *$ & $0.105 *$ & $0.114 *$ \\
& $(4.824$ & $(5.337$ & $(3.725$ & $(5.442$ & $(5.984$ & $(5.389$ & $(5.923$ & $(8.896$ & $(6.986$ & $(7.055$ & $(7.469$ & $(5.375$ & $(2.917$ & $(3.580$ \\
\hline \multirow{5}{*}{ agg } & $0.325 *$ & $0.363 *$ & $0.387 *$ & $0.427 *$ & $0.422 *$ & $0.417 *$ & $0.418 *$ & $0.397 *$ & $0.431 *$ & $0.470 *$ & $0.476 *$ & $0.271 *$ & $0.402 *$ & $0.283 *$ \\
& $(8.239$ & $(9.189$ & $(9.789$ & $(10.77$ & $(10.64$ & $(10.52$ & $(10.54$ & $(10.02$ & $(10.86$ & $(11.88$ & $(12.03$ & $(6.896$ & $(10.19$ & $(7.196$ \\
\end{tabular}


Note: the data in parentheses is the $\mathrm{Z}$ statistical value of Moran'I; *** means significant at $1 \%$ significance level.

Given the above mentioned, this paper discusses the mechanism of manufacturing industrial agglomeration's impact on pollution by constructing a spatial panel econometric model. This paper took pollution as the explained variable and industrial agglomeration as the explanatory variable. The settings of spatial panel data model was generally as follows:

$$
\left\{\begin{array}{l}
\mathrm{y}_{i t}=\tau y_{i, t-1}+\rho w_{i}^{\prime} y_{t}+x_{i t}^{\prime} \beta+d_{t}^{\prime} X_{i} \delta+\mu_{i}+\lambda_{t}+\varepsilon_{i t} \\
\varepsilon_{i t}=\lambda m_{i}^{\prime} \varepsilon_{t}+v_{i t}
\end{array}\right.
$$

In the Formula (3), ${ }_{i, t-1}$ was the first-order lag of the explained variable, $d_{t}^{\prime} X_{i} \delta$ was the spatial lag of the explanatory variable. Subject to different parameters, the model had three forms:

(1) When $\tau=0$, it was a spatial Doberman model (SDM).

(2) When $\tau=0$ and $\delta=0$, it was a spatial autoregressive model (SAR).

(3) When $\tau=0, \rho=0$, and $\delta=0$, it was a spatial error model (SEM).

Applying the three spatial econometric models to this paper, we can obtain:

(1) The Spatial Doberman Model (SDM) for environmental pollution:

$$
\begin{aligned}
& \operatorname{lnpolution~}_{i t}=\beta_{0}+\rho W_{\mathrm{it}} \ln _{\text {polution }_{i t}}+\beta_{1} \mathrm{agg}_{i t}+\beta_{2} \text { tech }_{i t}+\beta_{3} \text { stru }_{i t}+\beta_{4} F D I_{i t} \\
& +\beta_{5} e g d p_{i t}+\beta_{6} e d u_{i t}+\beta_{7} \text { pop }_{i t}+\beta_{8} e c_{i t}+\delta_{1} W_{\mathrm{it}} \operatorname{agg}_{i t}+\delta_{2} W_{\mathrm{it}} \text { tech }_{i t}+\delta_{3} W_{\mathrm{it}} \text { str }_{i t} \\
& +\delta_{4} W_{\mathrm{it}} \mathrm{fdi}_{i t}+\delta_{5} W_{\mathrm{it}} e \operatorname{con}_{i t}+\delta_{6} W_{\mathrm{it}} e d u_{i t}+\delta_{7} W_{\mathrm{it}} \text { pop }_{i t}+\delta_{8} W_{\mathrm{it}} e c_{i t}+\mu_{i}+\lambda_{t}+\varepsilon_{i t}
\end{aligned}
$$

(2) TheSpatial Lag Model (SAR) for environmental pollution:

$$
\begin{aligned}
& \text { Inpolution }_{t t}=\beta_{0}+\rho W_{\mathrm{it}} \text { Inpolution }_{i t}+\beta_{1} \mathrm{agg}_{i t}+\beta_{2} \text { tech }_{i t}+\beta_{3} \text { str }_{i t}+\beta_{4} \mathrm{fdi}_{i t} \\
& +\beta_{5} \text { econ }_{i t}+\beta_{6} e d u_{i t}+\beta_{7} \text { pop }_{i t}+\beta_{8} e c_{i t}+\mu_{i}+\lambda_{t}+\varepsilon_{i t}
\end{aligned}
$$

(3) TheSpatial Error Model (SEM) for environmental pollution:

$$
\begin{aligned}
& \operatorname{lnpolution}_{i t}=\beta_{0}+\beta_{1} \text { agg }_{i t}+\beta_{2} \text { tech }_{i t}+\beta_{3} \text { str }_{i t}+\beta_{4} F D I_{i t}+\beta_{5} e \operatorname{con}_{i t}+\beta_{6} e d u_{i t} \\
& +\beta_{7} \text { pop }_{i t}+\beta_{8} e c_{i t}+\mu_{i}+\lambda_{t}+\varepsilon_{i t}
\end{aligned}
$$

In the Formulas (4)-(6), it represents the $t^{\text {th }}$ year of the $i^{\text {th }}$ region. $\rho$ is spatial autoregressive coefficient, $\mathrm{W}_{\mathrm{it}}$ is spatial weight matrix, $\beta$ is the coefficient of explanatory variable and control variable, $\delta$ refers to the spatial coefficient of explanatory variable, $\mu_{\mathrm{i}}$ represents spatial effect, $\lambda_{\mathrm{t}}$ is time effect, $\varepsilon_{\mathrm{it}}$ is random error term. This paper adopted the adjacency weight matrix (W1) as the spatial weight matrix $\left(\mathrm{W}_{\mathrm{it}}\right)$. LM test results determines the spatial econometric model in use. This paper uses maximum likelihood estimation (MLE) for effective estimation for which has been more effective than the traditional OLS estimation.

\section{Results of the empirical research}

4.1. Spatial econometric analysis at the national level

According to the previous analysis, historical studies suggest that technological innovation and industrial structure optimization play a prominent role in forming the concept framework of how manufacturing industry agglomeration affects pollutant emissions. Therefore, to effectively verify the channel function played by technological innovation and industrial structure, this paper includes the manufacturing industry agglomeration, technological innovation and industrial structure into the regression model of Models 1 to 4 
on the basis of controlling other variables. The paper determined the spatial panel econometric form for the four models by calculating LM statistics. The LM robust statistics of SLM passed the 5\% significance test, while the LM robust statistics of SEM did not pass the test, suggesting that the model may have spatial lag items rather than spatial error items. Given the test result, the four models took the form of spatial panel lag for econometric regression. The results are shown in Table 2.

Table 2 shows that from Model 1 to Model 4, the influence coefficient of manufacturing industry agglomeration was significantly positive at $1 \%$ significance level, indicating that manufacturing industry agglomeration increased pollution. In Model 1 (without technological innovation and industrial structure variables), the influence coefficient of manufacturing industry agglomeration was 1.873 . In Model 2 (with technological innovation variable), the influence coefficient of manufacturing industry agglomeration was 1.920 , and the influence of technological innovation on pollution was significantly negative at $1 \%$ significance level. In Model 3 (with industrial structure variable), the influence coefficient of manufacturing industry agglomeration and industrial structure were 1.685 and 2.468 , respectively, while the industrial structure's influence on pollution was significantly positive at 5\% significance level. In Model 4 (with technological innovation and industrial structure variables), the influence coefficient of manufacturing industry agglomeration decreased to 1.734 , shows that technological innovation and industrial structure optimization play an important role in the relationship between manufacturing industry agglomeration and environmental pollution.

Table 2. Spatial econometric regression results at the national level

\begin{tabular}{|c|c|c|c|c|c|c|}
\hline Variable & Model 1 & Model2 & Model 3 & Model 4 & Model 5 & Model 6 \\
\hline $\operatorname{lnagg}$ & $\begin{array}{l}1.873 * * * \\
(3.36)\end{array}$ & $\begin{array}{l}1.920 * * * \\
(3.58)\end{array}$ & $\begin{array}{l}1.685 * * * \\
(3.06)\end{array}$ & $\begin{array}{l}1.734 * * * \\
(3.10)\end{array}$ & $\begin{array}{l}1.336^{*} \\
(1.78)\end{array}$ & $\begin{array}{l}2.388 * * * \\
(5.23)\end{array}$ \\
\hline $\operatorname{lnagg}^{2}$ & & & & 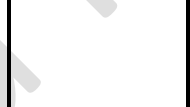 & $\begin{array}{l}-0.428 * \\
(-0.93)\end{array}$ & \\
\hline tech & & $\begin{array}{l}-1.347 * * * \\
(-3.01)\end{array}$ & & $\begin{array}{l}-1.349 * * \\
(-3.04)\end{array}$ & $\begin{array}{l}-1.243 * \\
(-2.22)\end{array}$ & $\begin{array}{l}-0.857 \\
(-0.21)\end{array}$ \\
\hline stru & & & $\begin{array}{l}2.468 * * \\
(1.97)\end{array}$ & $\begin{array}{l}2.767 * \\
(1.85)\end{array}$ & $\begin{array}{l}2.779 * \\
(1.77)\end{array}$ & $\begin{array}{l}-0.043 \\
(-1.58)\end{array}$ \\
\hline $\mathrm{fdi}$ & $\begin{array}{l}0.684 * * * \\
(13.76)\end{array}$ & $\begin{array}{l}0.687 * * * \\
(10.63)\end{array}$ & $\begin{array}{l}0.686 * * * \\
(10.49)\end{array}$ & $\begin{array}{l}0.675 * * * \\
(10.04)\end{array}$ & $\begin{array}{l}0.664 * * * \\
(8.88)\end{array}$ & $\begin{array}{l}0.495 * * * \\
(11.47)\end{array}$ \\
\hline er & $\begin{array}{l}-0.238 \\
(-1.07)\end{array}$ & $\begin{array}{l}-0.239 \\
(-1.07)\end{array}$ & $\begin{array}{l}-0.147 \\
(-0.64)\end{array}$ & $\begin{array}{l}-0.192 \\
(-0.78)\end{array}$ & $\begin{array}{l}-0.156 \\
(-0.77)\end{array}$ & $\begin{array}{l}-0.344 * \\
(-2.24)\end{array}$ \\
\hline econ & $\begin{array}{l}-3.827 * * * \\
(-7.5)\end{array}$ & $\begin{array}{l}-4.030 * * * \\
(-7.98)\end{array}$ & $\begin{array}{l}-4.077 * * * \\
(-7.98)\end{array}$ & $\begin{array}{l}-4.034 * * * \\
(-9.41)\end{array}$ & $\begin{array}{l}-4.055 * * * \\
(-8.92)\end{array}$ & $\begin{array}{l}-3.734 * * * \\
(-10.75)\end{array}$ \\
\hline pop & $\begin{array}{l}-2.783 * * * \\
(-2.79)\end{array}$ & $\begin{array}{l}-2.785 \text { *** } \\
(-3.57)\end{array}$ & $\begin{array}{l}-2.517 \text { *** } \\
(-3.22)\end{array}$ & $\begin{array}{l}-2.609 * * * \\
(-3.02)\end{array}$ & $\begin{array}{l}-2.802 * * * \\
(-4.03)\end{array}$ & $\begin{array}{l}-0.109 \\
(-0.05)\end{array}$ \\
\hline edu & $\begin{array}{l}-1.924 * * * \\
(-6.17)\end{array}$ & $\begin{array}{l}-1.859 * * * \\
(-5.59)\end{array}$ & $\begin{array}{l}-1.908 * * * \\
(-5.70)\end{array}$ & $\begin{array}{l}-1.965 * * * \\
(-6.74)\end{array}$ & $\begin{array}{l}-1.942 * * * \\
(-6.82)\end{array}$ & $\begin{array}{l}-2.040 * * * \\
(-9.41)\end{array}$ \\
\hline $\mathrm{N}$ & 3523 & 3523 & 3523 & 3523 & 3523 & 3523 \\
\hline log-likelihood & -11907.061 & -11904.106 & -11905.460 & -11902.413 & -11902.101 & \\
\hline $\mathrm{R}^{2}$ & 0.223 & 0.236 & 0.234 & 0.247 & 0.249 & 0.2003 \\
\hline
\end{tabular}




\begin{tabular}{|l|l|l|l|l|l|l|}
\hline \hline$\rho$ & 0.334 & 0.331 & 0.335 & 0.332 & 0.332 & 0.4909605 \\
\hline$\sigma^{2}$ & 41.079 & 41.089 & 41.127 & 41.138 & 41.142 & 6.7314533 \\
\hline $\mathrm{F}$ & & & & & & $10.48 * * *$ \\
\hline
\end{tabular}

Note: the data in parentheses is the $\mathrm{T}$ or $\mathrm{Z}$ statistical value; ***,**,* means significant at $1 \%, 5 \%, 10 \%$ significance levels, respectively.

Model 5 , by contrast, introduced the quadratic term of manufacturing industry agglomeration to test the existence of nonlinear relationship between manufacturing industry agglomeration and pollution. According to the results, the influence coefficient of manufacturing industry agglomeration's quadratic term was significantly negative, indicating that the pollution follows an inverted "U"-shaped relationship with the manufacturing industry agglomeration. As more manufacturers clustered, the environment gets more polluted until the inflection point appeared. By calculation, the inflection point emerges when the manufacturing industry agglomeration reaches 0.652 . Among the 271 prefecture-level cities, 173 cities were at upper left position of the inverted " $U$ " -shaped curve. The result pointed out that most Chinese prefecture-level cities in China were facing severe environmental pollution.

Model 5 demonstrated how these control variables impacted pollutions in the environment. Technology innovation has a negative effect on environmental pollution, which passed the $10 \%$ significance test. Technological innovation transforms productivity and develops clean technologies that promotes energy saving. Industrial structure had a significant positive effect on environmental pollution, which indicated that an industry-dependent economic structure has more serious pollutant problems. High energy consumption, high emission and low-tech industries make a large share of Chinese industrial structure. The positive effect of FDI on environmental pollution was significant at $1 \%$ significance level. As FDI concentrated in the resource- and labor-intensive enterprises in China, the growth of such firms increases pollution. Environmental regulation's effect on environmental pollution did not pass the significance test, indicating that the stronger supervision and pollution control by local government did not have distinctive effect in terms of manufacturing industry. The negative effects of economic development, population and education on environmental pollution were significant at $1 \%$ significance level, which indicated the improvement in these three factors are helpful to contain pollution.

Model 6 was the estimation of fixed effect model of the static panel. Compared with Model 5, we found that the influence coefficient of manufacturing industry agglomeration, like other control variables, on environmental pollution was relatively high regardless of the influence of spatial externality. If the spatial externality was not considered, it was easy to overestimate the effect of manufacturing industry agglomeration and most other control variables on environmental pollution.

\subsection{Spatial econometric analysis at the regional level}

Since China's regional economy is unbalanced, there may be significant differences between manufacturing industry agglomeration and pollution. In light of this, it is necessary to explore the regional heterogeneity characteristics of manufacturing industry agglomeration's impact on pollution. Through the LM, SLM and SEM tests and the hausman test of regression results for the eastern, northeastern, central and western regions respectively, the SEM of random effect would be appropriate for testing the eastern region, the SLM of random effect fit for the western and northeast regions, and the SLM of fixed effect should be used in the central region. The spatial econometric regression results are shown in Table 3. 
Models 13 and 14 introduced the quadratic term and cubic term of manufacturing industry agglomeration respectively. The influence coefficient of manufacturing industry agglomeration was not significant, meaning the manufacturing industry agglomeration in the northeastern region was not the direct cause to pollution. Models 7 and 8 showed that the influence coefficient of manufacturing industry agglomeration in the eastern and western regions was significantly negative at $5 \%$ and $10 \%$ significance levels, respectively, suggesting the industrial clusters in the two regions increased pollution. In Model 9, the influence coefficient of manufacturing industry agglomeration in the central region was positive, yet not pass the significance test. Models 10 and 11 introduced the quadratic term and cubic term of manufacturing industry agglomeration in the central region in turn and found the effect of the cubic term of manufacturing industry agglomeration on environmental pollution was significantly positive at $5 \%$ significance level. Thus, the relationship between manufacturing industry agglomeration and pollution in the central region follows a distinctive "N"-shaped curve. The effect of manufacturing industry agglomeration on pollution increased first before dropped, then it bounced back and finally went up with the increasing manufacturing industry agglomeration. The two inflection points of manufacturing industry agglomeration level were 0.532 and 0.891 , respectively. In the 80 prefecture-level cities in the central region, 15 of them have a manufacturing industry agglomeration level below 0.532 and 43 cities were above 0.891 . Given this, $72.5 \%$ of prefecture-level cities in the central region follows the rising trend of the " $\mathrm{N}$ " -shaped curve. The manufacturing industry agglomeration level in most prefecture-level cities fell between the two inflection points. The higher the manufacturing industry agglomeration level, the more serious the environmental pollution. In Model 12, manufacturing industry agglomeration in the northeastern region had a non-significant linear relationship with pollution. Models 13 and 14 introduced the quadratic and cubic terms of manufacturing industry agglomeration. The influence coefficient of industrial agglomeration was not significant, which indicated that there was no clear causality between manufacturing industry agglomeration and environmental pollution in the northeastern region.

Table 3. Spatial econometric regression results at the regional level

\begin{tabular}{|c|c|c|c|c|c|c|c|c|}
\hline \multirow{2}{*}{ Variable } & \multirow{2}{*}{\begin{tabular}{|l} 
Eastern \\
China
\end{tabular}} & \multirow{2}{*}{$\begin{array}{l}\begin{array}{l}\text { Western } \\
\text { China }\end{array} \\
\text { Model } 8\end{array}$} & \multicolumn{3}{|c|}{ Central China } & \multicolumn{3}{|c|}{ Northeastern China } \\
\hline & & & Model 9 & Model 10 & Model 11 & Model 12 & Modle 13 & Model 14 \\
\hline lnagg & $\begin{array}{l}0.790 * * \\
(2.31)\end{array}$ & $\begin{array}{l}3.167 * * \\
(2.36)\end{array}$ & $\begin{array}{l}1.422 \\
(1.64)\end{array}$ & $\begin{array}{l}0.096 \\
(0.07)\end{array}$ & $\begin{array}{l}0.635 \\
(0.46)\end{array}$ & $\begin{array}{l}-0.056 \\
(-0.07) \\
\end{array}$ & $\begin{array}{l}0.233 \\
(0.15)\end{array}$ & $\begin{array}{l}-1.149 \\
(-0.61) \\
\end{array}$ \\
\hline $\operatorname{lnagg}^{2}$ & & & & $\begin{array}{l}-1.522 \\
(-1.41) \\
\end{array}$ & $\begin{array}{l}3.422 \\
(1.50)\end{array}$ & & $\begin{array}{l}0.081 \\
(0.09)\end{array}$ & $\begin{array}{l}-3.771 \\
(-1.38) \\
\end{array}$ \\
\hline $\operatorname{lnagg}^{3}$ & & & & & $\begin{array}{l}3.053 * * \\
(2.47)\end{array}$ & & & $\begin{array}{l}-1.725 \\
(1.27)\end{array}$ \\
\hline tech & $\begin{array}{l}-0.854 * * * \\
(-3.86)\end{array}$ & $\begin{array}{l}-3.520 * * \\
(-2.24)\end{array}$ & $\begin{array}{l}-3.519 * * * \\
(-4.64)\end{array}$ & $\begin{array}{l}-3.341 * * * \\
(-3.66)\end{array}$ & $\begin{array}{l}-3.226 * * * \\
(-3.26)\end{array}$ & $\begin{array}{l}-9.528 * * * \\
(-3.11)\end{array}$ & $\begin{array}{l}-8.940 * * * \\
(-2.22)\end{array}$ & $\begin{array}{l}-9.274 * * * \\
(-2.33)\end{array}$ \\
\hline str & $\begin{array}{l}2.890 * * * \\
(3.11)\end{array}$ & $\begin{array}{l}12.5^{* * * *} \\
(3.28)\end{array}$ & $\begin{array}{l}16.354 * * * \\
(6.93)\end{array}$ & $\begin{array}{l}16.198 * * * \\
(6.36)\end{array}$ & $\begin{array}{l}15.629 * * * \\
(5.60)\end{array}$ & $\begin{array}{l}0.849 \\
(0.45)\end{array}$ & $\begin{array}{l}0.965 \\
1.48) \\
\end{array}$ & $\begin{array}{l}0.365 \\
(0.16) \\
\end{array}$ \\
\hline fdi & $\begin{array}{l}0.812 * * * \\
(5.52)\end{array}$ & $\begin{array}{l}0.697 \\
(1.59)\end{array}$ & $\begin{array}{l}0.598 * * * \\
(4.71)\end{array}$ & $\begin{array}{l}0.564 * * * \\
(4.04)\end{array}$ & $\begin{array}{l}0.597 * * * \\
(5.04)\end{array}$ & $\begin{array}{l}0.854 * * * \\
(2.71)\end{array}$ & $\begin{array}{l}0.795^{*} \\
(2.31)\end{array}$ & $\begin{array}{l}902 * * * \\
(3.02)\end{array}$ \\
\hline er & $\begin{array}{l}-0.047 \\
(-0.35)\end{array}$ & $\begin{array}{l}-0.410 \\
(-0.65) \\
\end{array}$ & $\begin{array}{l}0.342 \\
(0.95) \\
\end{array}$ & $\begin{array}{l}0.431 \\
(1.46)\end{array}$ & $\begin{array}{l}0.422 \\
(1.4)\end{array}$ & $\begin{array}{l}-0.219 \\
(-0.564)\end{array}$ & $\begin{array}{l}-0.139 \\
(-0.40) \\
\end{array}$ & $\begin{array}{l}-0.183 \\
(-0.51) \\
\end{array}$ \\
\hline econ & $\begin{array}{l}-1.990 * * * \\
(-5.14)\end{array}$ & $\begin{array}{l}-3.836 * * * \\
(-5.27)\end{array}$ & $\begin{array}{l}-6.865 * * * \\
(-8.06)\end{array}$ & $\begin{array}{l}-6.933 * * * \\
(-7.35)\end{array}$ & $\begin{array}{l}-7.024 * * * \\
(-7.51)\end{array}$ & $\begin{array}{l}-5.956 * * * \\
(-6.33)\end{array}$ & $\begin{array}{l}-6.010 * * * \\
(-5.76)\end{array}$ & $\begin{array}{l}-6.100 * * * \\
(-5.72)\end{array}$ \\
\hline
\end{tabular}




\begin{tabular}{|l|l|l|l|l|l|l|l|l|}
\hline \hline \multirow{2}{*}{ pop } & $\begin{array}{l}0.125 \\
(0.26)\end{array}$ & -0.509 & $-3.140 * * *$ & $-3.771 * * *$ & $-3.670 * * *$ & -2.086 & $-2.203 *$ & $-2.410 *$ \\
& $(-0.25)$ & $(-2.6)$ & $(-3.54)$ & $(-2.64)$ & $(1.55)$ & $(-2.15)$ & $(-1.78)$ \\
\hline \multirow{2}{*}{ du } & $-1.040 * * *$ & $-4.550 * * *$ & $-1.411 * * *$ & $-1.324 * * *$ & $-1.233 *$ & $-1.102 *$ & $-1.059 *$ & -0.989 \\
& $(-4.39)$ & $(-7.67)$ & $(-2.78)$ & $(-2.63)$ & $(-2.14)$ & $(-1.7)$ & $(-1.62)$ & $(-1.38)$ \\
\hline $\mathrm{N}$ & 1131 & 910 & 1040 & 1040 & 1040 & 442 & 442 & 442 \\
\hline $\log -$ likelihood & -2866.683 & -3518.691 & -3246.643 & -3245.812 & -3243.337 & -1331.922 & -1331.849 & -1331.137 \\
\hline $\mathrm{R}^{2}$ & 0.355 & 0.2485 & 0.470 & 0.468 & 0.462 & 0.458 & 0.458 & 0.458 \\
\hline$\rho$ & & 0.161 & 0.304 & 0.302 & 0.305 & 0.155 & 0.155 & 0.158 \\
\hline$\sigma^{2}$ & 7.825 & 111.728 & 25.467 & 25.393 & 25.182 & 21.634 & 21.621 & 21.504 \\
\hline
\end{tabular}

Note: the data in parentheses is the $\mathrm{T}$ or $\mathrm{Z}$ statistical value of Moran'I; ***, **, * means significant at $1 \%$, $5 \%, 10 \%$ significance levels, respectively.

According to the regression results, the influence coefficient of manufacturing industry agglomeration was the highest in western region, then came the eastern region and the central region, while the northeastern region was the smallest. It was a result of the industrial structure adjustment in China over recent years. Most of the heavily polluted manufacturing enterprises moved from eastern China to the west, polluting the western China. In terms of the coefficient of control variables, industrial structure was the main reason for the pollution in the western region, as the influence coefficient was 12.5 and was significant at $1 \%$ significance level. The manufacturing industry agglomeration in the northeastern region had little effect on pollution, because the manufacturing industry agglomeration was not balanced. In the 34 prefecture-level cities in the northeastern region, 16 cities had an industrial agglomeration level below $0.6,8$ cities' manufacturing industry agglomeration level was above 1.0 , and 10 cities between 0.6 and 1 . Provinces with higher manufacturing industry agglomeration level and the ones with lower level coexisted in the same region. Thus, the impact on pollution and environment was mixed. The promotion effect and inhibition effect worked together, leading to statistically insignificant results.

\subsection{Robustness test}

This paper further used the instrumental variable (IV) for model estimation to avoid the endogenous problem of core explanatory variables in order to explore whether the above conclusions were still robust. The first-order of time lag of manufacturing industry agglomeration was selected as its IV mainly because first, the correlation coefficient between manufacturing industry agglomeration and its first-order of time lag was 0.923 , and passed the $1 \%$ significance test, which met the correlation requirement between IV and endogenous explanatory variable; Second, the pollution in the current period would not affect the manufacturing industry agglomeration state in the previous period, and the IV was also uncorrelated with the random disturbance term. The regression results of model estimation by IV are shown in Table 4.

Table 4. Robustness test results

\begin{tabular}{|l|l|l|l|l|l|l|}
\hline \multirow{2}{*}{ Variable } & Nationwide & Eastern & Western & Central & Northeastern \\
\cline { 2 - 7 } & Model 15 & Model 16 & Model 17 & Model 18 & Model 19 & Model 20 \\
\hline \multirow{2}{*}{ lnagg } & $1.369^{* *}$ & $1.327^{*}$ & $0.596^{*}$ & $2.401^{*}$ & -0.140 & 0.546 \\
& $(2.55)$ & $(1.85)$ & $(1.83)$ & $(1.71)$ & $(-0.14)$ & $(0.29)$ \\
\hline \multirow{2}{*}{$\operatorname{lnagg}^{2}$} & & $-0.815^{*}$ & & & 1.660 & 0.009 \\
& & $(-1.80)$ & & & $(0.92)$ & $(0.07)$ \\
\hline $\operatorname{lnagg}^{3}$ & & & & & $1.660^{*}$ & 0.088 \\
& & & & & $(1.65)$ & $(0.08)$ \\
\hline
\end{tabular}




\begin{tabular}{|l|l|l|l|l|l|l|}
\hline \hline tech & $-1.184 * * *$ & $-1.107 * * *$ & $-0.746 * * *$ & $-2.929 * *$ & $281.743 * * *$ & $-7.043 *$ \\
& $(-3.09)$ & $(-2.29)$ & $(-3.84)$ & $(-2.03)$ & $(7.13)$ & $(-1.84)$ \\
\hline \multirow{2}{*}{ str } & $4.068 * * *$ & $4.078 * * *$ & $2.583 * * *$ & $10.827 * * *$ & $8.268 * * *$ & 2.044 \\
& $(2.82)$ & $(2.69)$ & $(2.9)$ & $(2.74)$ & $(3.54)$ & $(0.97)$ \\
\hline \multirow{2}{*}{ fdi } & $0.488^{* *}$ & $0.442 * *$ & $0.770 * * *$ & 0.702 & $1.183 * * *$ & $0.730 * *$ \\
& $(2.32)$ & $(1.94)$ & $(5.33)$ & $(1.59)$ & $(4.64)$ & $(2.49)$ \\
\hline \multirow{2}{*}{ er } & -0.174 & -0.137 & -0.092 & -0.527 & $0.628 * * *$ & -0.075 \\
\hline \multirow{2}{*}{ econ } & $(-0.75)$ & $(-0.72)$ & $(-0.73)$ & $(-0.85)$ & $(2.76)$ & $(-0.22)$ \\
\hline \multirow{2}{*}{ pop } & $-3.296 * * *$ & $-3.328 * * *$ & $-1.506 * * *$ & $-3.089 * * *$ & $-5.325 * * *$ & $-6.268 * * *$ \\
& $(-7.74)$ & $(-7.34)$ & $(-3.85)$ & $(-4.19)$ & $(-6.38)$ & $(-5.77)$ \\
\hline edu & $-1.663 * * *$ & $-1.785 * * *$ & 0.374 & 0.506 & -1.680 & $-1.244 *$ \\
& $(-2.17)$ & $(-2.92)$ & $(0.87)$ & $(0.27)$ & $(-0.66)$ & $(-1.75)$ \\
\hline $\mathrm{N}$ & $-2.394 * * *$ & $-2.371 * * *$ & $-1.211^{* * *}$ & $-4.335 * * *$ & $-0.996 * *$ & -1.717 \\
\hline $\log -$ likelihood & $(-8.51)$ & $(-8.83)$ & $(-5.15)$ & $(-7.41)$ & $(-2.46)$ & $(-1.3)$ \\
\hline R2 & 3252 & 3252 & 1044 & 840 & 960 & 408 \\
\hline
\end{tabular}

Note: the data in parentheses is the $\mathrm{T}$ or $\mathrm{Z}$ statistical value of Moran'I; ***, **, * means significant at $1 \%$, $5 \%, 10 \%$ significance levels, respectively.

In Model 15, the influence coefficient of nation-wide manufacturing industry agglomeration was significantly negative at the $10 \%$ significance level, indicating that manufacturing industry agglomeration has a significant positive impact on environmental pollution. The results in Model 16 remain robust despite the addition of the quadratic term. In Model 17 and 18, the regional-specific influence coefficient of manufacturing industry agglomeration in eastern and western China was significantly positive at the $10 \%$ significance level, revealing their significant negative linear relationship in these two regions. In model 19, the linear, quadratic terms of manufacturing industry agglomeration did not pass the significance test, but the cubic terms passed the $10 \%$ significance test in the central region, showing an " $\mathrm{N}$ "-shaped curve. The linear, quadratic and cubic terms of manufacturing industry agglomeration in the northeastern region did not pass the significance test, indicating a vague relationship between the two subjects in northeastern regions. The above regression results verify the robustness of this paper's conclusions.

\section{Conclusions and policy implications}

To find out the relationship between industrial agglomeration and environmental pollution, this paper carried out empirical research on the panel data collected from 271 prefecture-level cities in China from 2005 to 2018 through a spatial panel econometric model.

(1) The results detected an inverted " $U$ " -shaped relationship between manufacturing industry agglomeration and environmental pollution nation-wide. The manufacturing industry agglomeration level at the inflection point was 0.652 , suggesting that prefecture-level cities suffered severe environmental pollution problems. Tech-innovation and industry structure optimization play a vital role in the relationship between manufacturing industry agglomeration and environmental pollution. On the one hand, technological innovation resolves pollution as a control variable. On the other hand, it enhanced the positive impact of manufacturing industry agglomeration have on environmental pollution as a channel variable. 
(2) At the regional level the manufacturing industry agglomeration in eastern and western China had a significant adverse effect on environmental pollution. In the central China, the relationship between manufacturing industry agglomeration and pollution was "N" -shaped. To be more specific, the manufacturing industry agglomeration of most prefecture-level cities concentrated in the upward part of the "N" -shaped curve, having a significant positive effect on pollution. By contrast, the relationship between manufacturing industry agglomeration and environmental pollution was not clear in the northeastern region.

(3) Environmental pollution had an obvious spatial spillover effect. Omitting the spatial externality may cause the researchers to overestimate the effect of manufacturing industry agglomeration on environmental pollution.

(4) Technological innovation, economic development, population and education had a significant negative impact on environmental pollution, while industrial structure and FDI had a significant positive impact on environmental pollution. The impact of environmental regulation on pollution is insignificant.

Based on the above conclusions, we offer the following policy suggestions:

(1) Strengthen government guidance, optimize industrial layout and promote industrial cluster construction. The empirical research results suggested that the manufacturing industry agglomeration and pollution are positively correlated, but the increment pattern between the two was "U" -shaped. The positive effect on environmental pollution increased when the level of manufacturing industry agglomeration was below 0.652 and decreased after crossing this inflection point. By implementing appropriate regional and industrial policies, the government may better promote a more efficient regional development where the industrial agglomeration is transforming into industrial clusters with standardized governance.

(2) Strengthen enterprises' capacity to innovate, upgrade production equipment, improve pollution treatment and develop clean energy. The firms might try to improve environment through higher productivity and give full play to innovation's compensation effect. In particular, it is necessary to promote technology transfer and knowledge spillover, and jointly deal with pollution by establishing a coordinated "production, education and research" development models. Besides, strengthen the correlation effect between industrial agglomeration and technology, and reduce pollution through the linkage mechanism of the two.

(3) Develop differentiated industrial agglomeration policies for different regions. The results of the empirical research show that industrial agglomeration in different regions had different relationship with pollution, so the government should coordinate the regional industrial layout in line with regional structure and spatial distribution. For example, governments in the eastern region may encourage independent innovate and guide enterprises with R \& D capability, high-end design and high value-added industries to cluster and expand. As for central and western regions, in addition to promote industrial agglomeration, local authorities should take stricter environmental regulations and measures to protect the fragile ecology to avoid the recurrence of "development before environment".

(4) Implement a package of policies including improving environmental protection supervision, increasing investment in environmental control and actively guiding industries to cluster to avoid the dilemma between the industrial agglomeration and reducing pollution. Regions should solve pollution issues based on local ecology and environment, and economic and social development. Governments pour more effort in regional industrial structure optimization and upgrading, coordinating resources and policies to encourage green innovation and R\&D. Regulators must strengthen environmental supervision, governance and other 
comprehensive measures to effectively solve pollution issues. Due to the strong spatial correlation cross-regions, pollution treatment also needs inter and intra-government collaboration.

\section{References}

Andersson, M., Loof, H. (2011). Agglomeration and productivity: evidence from firm-level data. Annals of Regional Science, 46(3), 601-620.

Anselin, L. (1998). Spatial Econometrics: Methods and Models. Dordrecht: Kluwer Acadmeic Publishers.

Cao, J., Lin, Y. (2016). An empirical research on the relationship between Chinese manufacturing agglomeration and environmental pollution. Ecological Economy, 32(6).

Cetin, C., Karafaki, F.C (2020). The influence of green areas on city-dwellers' perceptions of air pollution: The case of Nigde city center. Journal of Environmental Biology, 41(2SI), 453-461.

Chen, J.J., Hu, C.G. (2008). The agglomeration effect of industrial agglomeration: a theoretical and empirical analysis of the Yangtze River Delta subregion. Management World, (6), 68-83.

Dasgupta, Susmita, Laplante, Benoit, Wang, H., Wheeler, et al. (2002). Confronting the environmental Kuznets curve. Journal of Economic Perspectives.

Dong, B., Gong, J., Zhao, X. (2012). Fdi and environmental regulation: pollution haven or a race to the top? Journal of Regulatory Economics, 41(2), 216-237.

Feldman, Maryann, P. (1999). The new economics of innovation, spillovers and agglomeration: Are view of empirical studies. Economics of Innovation \& New Technology, 8(1), 5-25.

Fujita, M., Thisse, J.F. (2002). Economics of agglomeration [electronic resource]: cities, industrial location, and regional growth / University Avenue Undergraduate Journal of Economics.

Grossman, G.M., Krueger, A.B. (1992). Environmental impacts of a north American free trade agreement. CEPR Discussion Papers, 8(2), 223-250.

He, J. (2006). Pollution haven hypothesis and environmental impacts of foreign direct investment: the case of industrial emission of sulfur dioxide (so2) in Chinese provinces. Ecological Economics.

Jorgenson, K.A. (2007). The effects of primary sector foreign investment on carbon dioxide emissions from agriculture production in less-developed countries, 1980-99. International Journal of Comparative Sociology, 48(1), 29-42.

Leeuw, F.A.A.M.D., Moussiopoulos, N., Sahm, P. (2001). Urban air quality in larger conurbations in the European union. Environmental Modelling \& Software, 16(4), 399-414.

Li, W.N., Yang, Y.F., Wang, Z.Z. (2010). Manufacturing agglomeration, air pollution and energy-saving and emission-reduction - An empirical analysis based on the statistics of 30 manufacturing industries. Economic Management, 32(9).

Liang, F.H. (2006). Does foreign direct investment harm the host country's environment? Evidence from China. Social Science Electronic Publishing.

Liu, H., Liu, C.H., Yang, Q. (2015). Spatial spillover and the source of environment pollution - Empirical study on the perspective of network analysis. Economist, (10).

Liu, J., Liu, Y., Wang, X. (2019). An environmental assessment model of construction and demolition waste based on system dynamics: A case study in Guangzhou. Environmental Science and Pollution Research International.

Liu, Y.B., Yuan, H.X., Feng, Y.D. (2018). Spatial spillover and threshold effects for emisions reduction of industrial agglomeration. Journal of Applied Statistics and Management, 37(2).

Lu, Y., Wang, P., Zhu, X. (2017). Urbanization, spatial spillover and technological innovation - Based on 264 cities in China. Finance and Economics, (11).

Marion, Drut, Aurélie, Mahieux. (2015). Correcting agglomeration economies: How air pollution matters. Papers in Regional Science. 
Markusen, Ann. (1996). Sticky places in slippery space: A typology of industrial districts. Economic Geography.

Moriki, Hosoe, Tohru, Naito. (2006). Trans-boundary pollution transmission and regional agglomeration effects. Papers in Regional Science.

Ord, J.K., Getis, A. (2010). Local spatial autocorrelation statistics: distributional issues and an application. Geographical Analysis, 27(4), 286-306.

Porter, M. (1990). The Competitive Advantage of Nation. New York: Free Press.

Rena, W., Zhonga, Y., Meligranab, J., Andersonc, B., Wattc, W.E. (2004). Urbanization, land use, and water quality in shanghai. 1947-1996. Environment International, 29(5), 649-659.

Tan, J., Zhang, Y. (2015). Bonus of Industrial Agglomeration or Reappearance of "Pollution Haven"? Based on the Evidence in Guangdong Province. Economics and Management Research, (6), 82-89.

Taylor, B.R.C.S. (1995). Trade and transboundary pollution. American Economic Review, 85(4), 716-737.

Virkanen, J. (1998). Effect of urbanization on metal deposition in the bay of thlahti, southern finland. Marine Pollution Bulletin, 36(9), 729-738.

Wagner, U.J., Timmins, C.D. (2009). Agglomeration effects in foreign direct investment and the pollution haven hypothesis. Environmental \& Resource Economics, 43(2), 231-256.

Wang, S., Zhang, K., van Beek, L.P.H., Tian, X., Bogaard, T.A. (2020). Physically-based landslide prediction over a large region: Scaling low-resolution hydrological model results for high-resolution slope stability assessment. Environmental Modelling \& Software: With Environment Data News, 124, 104607.

Xie, R.H., Yuan, Y. (2006). Research on the pollution abatement effect of industrial agglomeration's evolution. Economic Review, (2), 18-28.

Yang, C., Gao, F., Dong, M. (2020). Energy efficiency modeling of integrated energy system in coastal areas. Journal of Coastal Research, 103(sp1), 995.

Yang, R.F. (2015). Industrial aggregation, foreign direct investment and environmental pollution. Economic Management, 37(2).

Yelmen, B., Sahin, H.H., Cakir, M.T. (2019). The use of artificial neural networks in energy use modeling in broiler farms: A case study of mersin province in the Mediterranean region. Applied Ecology and Environmental Research, 17(6), 13169-13183.

Yu, D., Mao, Y., Gu, B., Nojavan, S., Jermsittiparsert, K., Nasseri, M. (2020). A new LQG optimal control strategy applied on a hybrid wind turbine/solid oxide fuel cell/ in the presence of the interval uncertainties. Sustainable Energy, Grids and Networks, 21, 100296.

Zeng, D.Z., Zhao, L. (2009). Pollution havens and industrial agglomeration. Journal of Environmental Economics \& Management, 58(2), 141-153. 